\title{
Acquisition of Second Language Vocabulary for Kindergartners with Speech Sound Disorders
}

\author{
Tracy Lynn Zapf, Communication Disorders and Sciences, University of Oregon
}

\section{Abstract}

Researchers and educators alike have raised concerns over the potential exclusion of children with speech and language disorders in immersion programs. The purpose of this pilot study is to determine whether children with speech sound disorders acquire Spanish vocabulary at a rate comparable to typical peers when learning in an immersion program, and if rates of acquisition differ for expressive versus receptive vocabulary. Five kindergartners attending a partial, early elementary immersion school were studied: one control participant and four participants with speech sound disorders. This investigation used expressive (spoken) and receptive (understood) vocabulary probes to test the number of Spanish vocabulary words children could produce and comprehend within an eight-week period. Results show that children with speech sound disorders acquire expressive Spanish vocabulary at a rate comparable to their typical peers but had lower levels of acquisition overall, while rates of receptive vocabulary acquisition varied across participants. The results of this pilot study, which are not yet comprehensive, suggest that children with speech sound disorders are able to acquire Spanish vocabulary and, as a result, should continue to be included in immersion programs in the future.

\section{Introduction}

The American Speech-Language-Hearing Association (ASHA) website states that speech and language disorders (S/LD) are among the most common disabilities in the United States ("Incidence and Prevalence," 2008). The number of children who received services for speech or language disorders in fall 2003 was estimated at 1,460,583, not including children who had speech or language disorders secondary to another disorder (U.S. Dept. of Education, 2005); while the total number of children enrolled in elementary school in the United States in 2009 was 32,238,00o (U.S. Census Bureau, 2009). Given that close to $4.5 \%$ of children in elementary schools received services for speech and language disorders, it is clear that many children in the United States (US) are affected by these disorders such that their speech production, speech use, academic success, and even social participation may be disrupted (McCauley, 2004).

Second language learning represents one facet of academic success in the US educational system, which is a prerequisite for high school students applying to college, and is generally a requirement for university Bachelor of Arts students. Although the majority of children and young adults learning a second language participate in traditional foreign language education (such as foreign language in elementary school programming), an alternative method called 
immersion schooling has proven to be a successful method of educating children in a second language (Lambert \& Tucker, 1972).

Immersion schools have frequently been shown to benefit children from the regular educational track (e.g., Campbell, Gray, Rhodes \& Snow, 1985; Lambert \& Tucker, 1972; Turnbull, Lapkin \& Hart, 2001), yet the benefits of immersion schooling for children with S/LD, who could be considered atypical language learners, remain largely unstudied. Genesee (1987), an advocate for inclusion of children with S/LD in immersion schools, states, "If immersion is not good for all, it should not be offered to only a few; therefore, it becomes available to none" (Genesee, 1987). Consequently, it is important for children with S/LD, who make up a large number of the children in our schools, to have equal access to immersion schooling. Currently, it is not entirely clear what the benefits of immersion schooling are for such children, or the potential difficulties.

This pilot study aims to assess Spanish vocabulary acquisition over an eight-week period by English-speaking children with speech sound disorders (SSD) attending an immersion school. Although the scope of this study is not large enough to show definitively the success of children with SSD in immersion schooling, understanding their ability to acquire vocabulary is an important step toward addressing their academic success-or difficulties-in learning a second language. Sinatra (2008) states that understanding of vocabulary is strongly related to language comprehension and reading tasks and, ultimately, academic success. Therefore, assessments of vocabulary acquisition of students learning a second language are crucial to understanding whether these students will be academically successful in learning a second language. The aim of this pilot study is to analyze second language vocabulary acquisition for children with SSD in comparison to typical peers. The research questions that direct this investigation include:

1. Do kindergarten children with SSD acquire Spanish vocabulary at a rate similar to typical peers when learning in an immersion program?

2. If children with SSD acquire Spanish vocabulary through an immersion program, do their rates of acquisition for receptive (that which is spoken) versus expressive (that which is audibly understood) vocabulary differ?

\section{Speech and Language Disorders in Children}

Children with speech and language disorders (S/LD) are a heterogeneous group of children who experience difficulties with speech production and/or language comprehension (Dodd \& McIntosh, 2008). Speech is "the production...of the sounds that convey phonetic structure" while motor movement of body parts such as the tongue and mouth allow production of the elemental sounds, or phonemes, that make up the speech signal (Liberman \& Whalen, 2000). Language is a culturally shared code that allows any group of people to communicate with one another utilizing higher-level cognitive processing (Liberman \& Whalen, 2000). In order for both speaker and listener to recognize certain sounds as language, both must have a cognitive understanding of the language being spoken; their brains are trained to understand a speech sound of their cultural code, or language, over a sound that is not a part of their code (Liberman \& Whalen, 2000). Children with S/LD experience disruptions to speech, language, or both with varying degrees of severity and differences in etiology (cause), recovery, and social effects 
(Leonard, 1998; Webster \& Shevell, 2004; McCauley, 2004). Due to the integral role of speech and language in educational tasks, S/LD affect scholastic success as well as communication and socialization (Varley, 2008).

For a typically developing child, acquisition of speech and language occurs easily and without extensive scaffolding from parents. Young children still make some mistakes such as incorrect use of tense markers and pronunciation of some late developing sounds (such as /l/, /r/, /s/, /sh/, /ch/, /y/, /v/, /z/, and /th/) but the majority of their speech can be well understood ("National Institute," 2000). By age four or five, 80\% to 90\% of speech by a typically developing child can be understood (Hamaguchi, 2010). For children with S/LD, the process of acquiring and using speech and language is a challenge that requires aid beyond that of parents and classroom teachers. These children must meet with a speech-language pathologist (SLP) to work on tasks such as picture naming drills, joint book reading, dramatic play, computerized language comprehension exercises, and writing assignments (Leonard, 1998; Webster \& Shevell, 2004). These tasks encourage further interaction with language and speech than the child receives in their regular classroom experience (McGregor, n.d.).

\section{Speech Sound Disorders in Children}

Speech Sound Disorders (SSD) are some of the most common disorders of speech among school-aged children (Lewis et al., 2006), with an estimated prevalence of 2-13\% (Peterson \& McGrath, 2009). SSD encompass difficulties with phonetics (articulatory components) or phonemics (cognitive-linguistic processing) and affects populations with structural, perceptual, or neuromotor disorders (Bowen, 2009). There are two main subgroups within SSD that describe a child's SSD more specifically: articulation disorders and phonological disorders. Although current research combines these two terms into SSD, the names 'articulation' and 'phonological' are still used as lay terms to describe these disorders. Changes in terminology are common in the field of communication disorders and sciences due to new discoveries in research (Bowen, 1998). In general, an articulation disorder is associated with difficulties at a phonetic level (motor production of speech sounds), while a phonological disorder implies difficulties at the phonemic-linguistic (cognitive) level, which indicates trouble in organizing and understanding the speech sound system (Bowen, 2009; McCauley, 2004). Children with phonological disorders will typically experience difficulty with word production or will have an inadequate understanding of the phonological system that makes up speech, causing speech comprehension problems for the child. Children will sometimes produce sounds correctly in certain contexts and incorrectly in others. Often, they will shorten their sentences to minimize confusion experienced by the listener, and substitute or omit sounds in their speech production, affecting intelligibility (Dockrell \& Messer, 1999; Peterson \& McGrath, 2009). When a child has a purely articulatory problem, the cause is typically an oral-motor disorder, which manifests as incorrect production of sounds (Dockrell \& Messer, 1999; Peterson \& McGrath, 2009).

The etiology of SSD and other speech disorders is unknown for many individuals; however, there are some hypotheses to account for these differences. For example, researchers have recently identified a link between genetics and SSD, as many children diagnosed with SSD have SSD in their family history (Lewis et al., 2006; Dockrell \& Messer, 1999). Other potential causes 
of SSD include differences in IQ, socioeconomic status, speech development, motor skills, auditory discrimination, oral structures, hearing loss, and neuropathologies (Hegde, 1995). Yet most children with SSD have no known cause for what is considered their "functional speech disorder" (Bowen, 2009).

Impacts of SSD include problems with speech production and use, reduced intelligibility, risk for broader S/LD, academic difficulties, and social stigma (McCauley, 2004). SSD causes stress for the child struggling through speech production, as well as for parents and siblings who must listen closely to decipher and understand the child's speech (Bowen, 2009). Aside from these difficulties, studies have linked SSD with lower academic success. Felsenfeld, Broen, and McGue (1994) studied the long-term effects of a moderate phonological disorder in children whose disorders persisted past first grade, and compared them against a cohort of students who had typical articulation abilities in childhood. During the participant identification process, children who performed at least 1.5 standard deviations below the mean on the Prekindergarten Imitation Articulation Test-which assesses production of word-initial and word-final consonant singletons, as well as word-initial consonant clusters-were included in the phonological disorder cohort. Control participants had to score at or above the mean and have received no speech or language treatment. After 28 years, the investigators interviewed these students, recording their educational and occupational accomplishments. It was found that participants who had a moderate phonological disorder received lower grades in high school, required more academic help, and completed fewer years of formal education. In addition, this group tended to occupy jobs considered semiskilled or unskilled at a higher frequency than the control group. Although these results do not predict that any single child with a phonological disorder will be less successful in adulthood, Fesenfeld et al. (1994) conclude that a phonological disorder may be one facet in understanding how childhood speech problems might manifest in adulthood.

\section{Immersion Schooling}

Immersion schooling began in Quebec, Canada in 1965 at the St. Lambert French immersion program (Genesee, Paradis \& Crago, 2004), an educational initiative created to address the prevalence of both French and English language use in Canada. The first immersion program in the United States opened in 1971 as a Spanish total-immersion elementary school in Culver City, California (Genesee, 1987), created to address the increase of Spanish language use in the United States. Spanish is currently the most popular target language in U.S. immersion schools, although interest in other target languages is increasing (Christian, 1996). At immersion schools, children learn a majority or all of their school subjects in a second language, leading to the assumption that children will learn the second language much in the same way they learned their first language (Cummins \& Swain, 1986; Genesee et al., 2004). Teachers do not introduce the second language as a separate subject, but use it as a "vehicle" for instruction (Stewart, 2005). Participation in immersion schooling is usually voluntary, mostly based on parental decision (Christian, 1996). There are various models of immersion programs, including early, middle, or late immersion, as well as partial and total immersion. Early immersion typically begins in kindergarten or grade 1 , middle immersion in grades 4 or 5 , and late immersion in grades 6, 7, or 8 (Lazaruk, 2007). For partial immersion, students learn about $50 \%$ of the day in 
English, and 50\% in the target second language. Total immersion schools typically begin with $100 \%$ of instruction in the target second language, and gradually add classes taught in English over the course of following years (Genesee et al., 2004).

Immersion schooling differs from traditional foreign language classes in instructional methods. Students in immersion programs learn a second language through the instruction of other subjects given in that language, with little direct language instruction. Students in foreign language in elementary schools (FLES) programs learn through traditional foreign language instruction. As a result, students in immersion programs spend less time learning grammatical rules and vocabulary through rote memorization, yet are proven to have a superior understanding of their target second languages (Cummins \& Swain, 1986).

\section{Children with Speech and Language Disorders in Immersion Schools}

Studies conducted over the past 50 years have shown the overwhelming benefits of immersion schooling for the education of mainstream children in both native and second languages (Campbell, Gray, Rhodes \& Snow, 1985; Lambert \& Tucker, 1972; Turnbull, Lapkin \& Hart, 2001). By contrast, the suitability of immersion schooling for children with S/LD is less widely researched. Genesee, a leading advocate for the advantages of immersion schooling for all students, states, "It is imperative that educational decisions concerning exclusion of subgroups of students from immersion be founded on systematic objective investigation, and not on speculation or "common sense" (Genesee, 1987). Children with S/LD have never been systematically excluded from immersion schooling, though concerns of parents and educators have limited their enrollment in immersion schools, since parents and educators worry that having regular academic subjects taught through another language may be an unnecessary burden for these children (Genesee, 1987). Cummins and Swain (1986) also explain that "A commonly held view is that immersion education is only for children of above average intelligence" (Cummins \& Swain, 1986) because of the assumed difficulty of learning all school subjects in a second language. Research has proven, however, that this system does not burden children academically, and actually helps them achieve at high levels in all school subjects (Campbell et al., 1985; Lambert \& Tucker, 1972; Turnbull et al., 2001).

Bruck (1978) has conducted the most prominent research concerning language-impaired children in immersion settings. She conducted her research in Montreal, Quebec, and studied children with language difficulties in Canada's French immersion schools. Bruck's study included four groups of native English speaking children: (a) children with language impairments in French immersion classes, (b) children with language impairments in Englishonly classes, (c) typically functioning children in French immersion classes, and (d) typically functioning children in English-only classes. For this study, language screenings performed by the school identified those children with language impairments. The investigator studied these four groups from kindergarten to grade 3 by testing them on second language abilities, cognitive development, and school achievement. The results of this study revealed that children with language impairments were not only successful in their immersion program, but also outperformed children with language impairments in English-only settings. They did not succeed in academic achievement and second language acquisition as rapidly as those students 
without language impairments (both in the immersion setting and not), but this finding was expected given their pre-existing condition. Bruck concluded that because the languageimpaired children were successful in an immersion school, they should have the opportunity to learn in an immersion setting and not be excluded based on speculation. Bruck (1982), in a later commentary, notes that children with language impairments had higher levels of second language proficiency than non-immersion students, both with and without language impairments, in conventional second language courses. Additionally, she states that languageimpaired children cannot typically cope with traditional second language courses, as learning linguistic rules and structures by rote directly exposes their weaknesses.

Not all studies on children with language difficulties in immersion schools have yielded positive results. Trites (1981) examined the suitability of immersion schooling for children with a maturational lag of the temporal lobe, a region of the brain typically associated with language function. The participants in this study were students who possessed high IQs as well as good motor and sensory function, and yet performed poorly on the Tactual Performance Test (TPT), a psychomotor problem-solving test in which children place blocks into a foam board while blindfolded, alternating the blocks using the dominant hand, non-dominant hand, and then both hands. Trites concluded that poor performances on the TPT is a result of a maturational lag in the temporal lobe of the brain, and that students who performed poorly were also those students having trouble succeeding in French immersion schools. This conclusion counters the belief that all children are best suited to learn new languages at an earlier age: these deficits in second language ability imply that if these children had been taught in their native language, such problems would not have occurred. Trites repeated the study a year later with different students, and reached the same conclusion: despite normal intelligence and good socioeconomic background, some students are not fit for early immersion schools. Follow-up was done with students who had transferred out of immersion schooling, and it was determined that they were academically successful in an English-only educational setting. However, Genesee (1987) criticized Trites' study because it only dealt with English-speaking students having difficulty in French immersion schools, and did not find minority language students with the same profile having trouble learning English. Genesee (1987) pointed out that Trites' study suggested that this disability is specific to English-speaking children in French immersion schools, which seemed highly unlikely. For these results to be applicable to a greater population of students learning second languages, a study that yielded similar results and tested children learning a second language other than French would be necessary. As it is, Trites' conclusions (1981) were based on a narrow study sample and cannot be applied to a wide variety of students.

\section{Summary}

Research on immersion schooling for children with $\mathrm{S} / \mathrm{LD}$ has generally implied that students with S/LD are successful in learning a second language through immersion schooling, and should therefore have the opportunity to learn in such settings. Immersion schooling has proven academic benefits for most children, so children with S/LD should be considered for any academic advantage possible, since $\mathrm{S} / \mathrm{LD}$ negatively affect academic achievement. It is necessary for researchers to conduct more studies concerning the success of children with S/LD in 
immersion schools for consideration by parents and educators and to broaden the body of knowledge of this subject for speech language pathologists.

\section{Methods}

\section{Participants}

All participants in the study were kindergartners attending a partial-early immersion elementary school. All children were native English speakers learning Spanish as a second language. The investigator selected participants based on: (a) enrollment at the test school, (b) willingness of child and parents to participate, and (c) having English as a native language. The investigator recruited children with SSD based on their eligibility for speech therapy with a licensed speech-language pathologist (SLP) at the school and nomination of probable candidates by the SLP. The investigator called parents of children for recruitment, and parents completed a permission form drafted for the purpose of the study. The Institutional Review Board (IRB) of the University of Oregon approved all consent documents and study procedures.

Summarized participant information is found in Table 1 . The participants in the study were all five to six years of age and had speech and/or language disorder diagnoses with the exception of a control participant, designated $\mathrm{AB}$. $\mathrm{AB}$ was a five-year-old male with no speech or language difficulty. DC was a five-year-old female diagnosed with a SSD and a unilateral hearing impairment. DC started kindergarten with errors in the production of the following sounds /s/, /z/, /s/ blends, /f/, /v/, /sh/, /ch/, /j/, /th/, final /t/, and /d/. At the time of the study, she could produce most of these sounds correctly in conversation. DC struggled with peer social interaction that affected her learning. EF was a six-year-old female diagnosed with a SSD. She made errors in the following sounds $-/ \mathrm{k} /, / \mathrm{g} /, / \mathrm{f} /, / \mathrm{l} /, / \mathrm{th} /, / \mathrm{r} /$ blends, and /s/ blends, and had more difficulties with multisyllabic words. GH was a five-year-old male diagnosed with a SSD and a language disorder. The following sound errors characterized his articulation $-/ \mathrm{m} /, / \mathrm{r} /$, $/ \mathrm{v} /, / \mathrm{l} /, / \mathrm{th} /$ and $/ \mathrm{s} /$ blends. His language scores were at the seventh percentile with his receptive scores being much higher than his expressive scores. He used simplified sentences with many pronoun and verb tense errors. JK was a six-year-old male diagnosed with a SSD. At the beginning of kindergarten, his language scores were at the seventh percentile and he made errors in the following sounds $-/ \mathrm{k} /, / \mathrm{v} /, / \mathrm{ng} /, / \mathrm{y} /, / \mathrm{th} /, / \mathrm{ch} /, / \mathrm{z} /, / \mathrm{s} /, / \mathrm{r} /$, and $/ \mathrm{l} /$ blends. His phonological patterns showed consonant deletion (e.g. "no" for "nose"), consonant cluster reduction (e.g. "net" for "nest" and "tee" for "tree"), and occasionally consonant stopping (e.g., "tun" for "sun"). At the time of the study, the only sound he was still receiving therapy for was the /th/ sound.

"Class" listed below in Table 1 signifies whether children were in the same Spanish class or not; students in Class A learned together and students in Class B learned together. All four students in Classes A and B had the same Spanish teacher but had Spanish class at opposite times of day. Likewise, students in Class A and B had English with the same teacher but at opposite times of day (this schedule maintained a 50:50 ratio of Spanish to English instruction time). The student in Class $\mathrm{C}$ had different Spanish and English teachers and classrooms. 
All kindergarten Spanish teachers used the same Spanish class curriculum. The school sought to maintain an equal number of native Spanish and English speakers enrolled in each classroom to reinforce peer language assistance. Kindergartners learned Spanish and English literacy (in each respective language) at all times during the school year, and mathematics, science, and writing were taught alternately in English and Spanish, switching between the two languages every five units.

Table 1. Participant Profiles.

\begin{tabular}{lllll}
\hline Child & $\begin{array}{l}\text { Age (years; } \\
\text { months) }\end{array}$ & Sex & Diagnosis & Class \\
\hline AB & $5 ; 11$ & Male & No SSD & Class A \\
& $5 ; 11$ & Female & SSD & Class A \\
& & DC & Unilateral \\
& & & & Hearing \\
& & Female & SSD & Class B \\
EF & Male & SSD & Class B \\
& $5 ; 3$ & & GH & Language \\
& & & & Disorder \\
& & Male & SSD & Class C \\
\hline
\end{tabular}

In terms of the population at the study school, a total of 332 students were enrolled in grades $\mathrm{K}-5$ at the time of the study. Among the students at the school, $80.7 \%$ were considered economically disadvantaged, as indicated by the percent of students receiving free or reduced price lunches (Council of Chief State School Officers: School Matters, 2011). Demographic statistics from the school website show that $53.9 \%$ of the students identified as White, $1.8 \%$ as Black, $33.7 \%$ as Hispanic, $0.9 \%$ as Asian/Pacific Islander, and $2.1 \%$ as American Indian/Alaska Native ("Council," 2011).

\section{Procedures}

\section{Measures}

Measures for the study included a list of 25 Spanish vocabulary words chosen from the students' Spanish class curriculum. All vocabulary words from the first three units of kindergarten Spanish curriculum (those in the vocabulary word banks) were written down, and the words used more frequently in the classroom (determined through observation by the investigator) were chosen for the final list of 25 words. The investigator also chose words based on the criteria that they are high frequency (commonly used), concrete nouns, and fit into one of two categories: items found in school and body parts. See Appendix A for a complete list of words. The investigator created picture flashcards with clip art images (see Appendix B) of each word used in the three vocabulary probes (vocabulary testing sets). 


\section{Data Collection}

Participants completed four biweekly testing sessions over an eight-week period, with each session lasting about 15 minutes and taking place in the hallway or child's classroom in the school. At the first testing session only, the investigator administered an English expressive vocabulary probe as a data collection exercise and at all four sessions, two vocabulary probes were administered to measure receptive and expressive Spanish vocabulary acquisition. These two probes are the dependent variables of the study, and represent Spanish language expressive and receptive abilities of the children. An investigator, conversationally proficient in Spanish, administered the probes.

\section{English vocabulary probe}

The investigator administered the English vocabulary probe at the first testing session only, to determine if each child knew the vocabulary words in English. In order to be considered for continuation in the study, all students needed to know each Spanish vocabulary word in English; students were not expected to learn words in Spanish without previous knowledge of the English equivalent. For this probe, children were shown one picture flashcard at a time and asked to say the word in English. The investigator repeated this exercise for each word.

\section{Expressive vocabulary probe}

The investigator used the expressive vocabulary probe at each testing session to test the child's expressive, or spoken, abilities in Spanish. Children were shown one picture flashcard at a time, and asked to say the word in Spanish. The investigator repeated this exercise for each word.

\section{Receptive vocabulary probe}

The investigator administered the receptive vocabulary probe in a second exercise at each testing session, in order to test the child's receptive knowledge, or auditory understanding, of Spanish. The investigator would set out five picture flashcards at a time, stating a word in Spanish and asking the child to point to the picture of that word. The investigator repeated this exercise five times until all 25 words had been shown.

\section{Scoring}

For data calculation, the number of words correctly produced (expressive) and understood (receptive) by the child was divided by the total number of correct responses possible, 25. This created a percentage accurate for each probe (excluding the English vocabulary probe) that exemplifies the percentage of expressive or receptive vocabulary words the child appeared to know. The investigator considered expressive answers correct when the child produced a word with the correct syllabic structure; specifically, with the correct number of syllables, correctly stressed syllables, and with CV (consonant-vowel) structure intact. Words were sufficiently near target and considered correct when their production met the above criteria and no more than one phonemic insertion or substitution of either a vowel or consonant was made. The investigator considered receptive vocabulary correct when the child pointed clearly at a flashcard in response to the stated word. 
At one testing session, a reliability coder (a secondary person tasked with scoring the expressive and receptive abilities of the children alongside the primary investigator) calculated point-by-point agreement for expressive and receptive vocabulary accuracy. The reliability coder, together with the investigator, scored whether a child expressed or demonstrated comprehension of words accurately, following the same inclusion criteria. The reliability coder and investigator compared scores given independently to each child during each probe, determining if both felt the production reflected that the child had learned the word. The reliability coder was a native Spanish speaker and certified SLP employed at the study school. The reliability coder participated at only one testing session to verify that the inclusion criteria employed by the investigator was an accurate representation of the children's vocabulary understanding. If the same inclusion criteria were followed in a subsequent study, baring human error, the same inter-rater reliability percentage would most likely be achieved. The investigator calculated inter-rater reliability for this pilot study at $100 \%$.

\section{Results}

Data from the probe sessions shows the percentage of vocabulary words (out of 25) each child could accurately express and understand receptively per testing session. Scores on the two dependent variables are calculated as percentages by dividing the number of words correctly expressed or receptively understood by the total number of words possible, and then multiplying by 100. Each figure lists percentage of words accurately expressed or receptively understood per probe session per child. As Figure 1 shows, control participant AB increased 12\% (from 56\% to $68 \%$ accuracy) on the expressive vocabulary probe. On the receptive probe, he also increased $12 \%$ (88\% to $100 \%$ ). Figure 2 shows that DC increased $32 \%$ on the expressive vocabulary probe ( $4 \%$ to $36 \%$ ). On the receptive probe, she increased $16 \%$ (68\% to $84 \%$ ). According to Figure 3 , $\mathrm{EF}$ increased $8 \%$ on the expressive probe (36\% to $44 \%$ ), and increased $4 \%$ on the receptive vocabulary probe (96\% to $100 \%$ ). As Figure 4 illustrates, GH increased $8 \%$ on the expressive vocabulary probe ( $0 \%$ to $8 \%$ ), and decreased $8 \%$ on the receptive vocabulary probe (68\% to $60 \%$ ). The investigator should note that data for $\mathrm{GH}$ was used from his second and final session instead of first and final session due to his absence from school on the first testing day. Figure 5 shows that JK increased $8 \%$ on the expressive vocabulary probe (12\% to $20 \%$ ), and increased $0 \%$ on the receptive probe (60\% to 60\%). Overall, the participants with SSD increased in the number of words produced accurately on the expressive vocabulary probe, an average of $14 \%$ from the first to the final testing session. On the receptive vocabulary probe, all children but one increased in their knowledge of receptive vocabulary, an average of $3 \%$ from the first to the final testing session (or $6.67 \%$ excluding the child who decreased from the first to the final session).

The investigator calculated a paired $t$-test, which assesses whether the means of two groups of data are statistically different from one another, to determine whether the number of words learned from the first to the final session represented a significant increase for the children with SSD. The results were not significant for the expressive vocabulary $(\mathrm{t}(3)=2.33 ; \mathrm{p}=.10)$ or receptive vocabulary $(\mathrm{t}(3)=.60 ; \mathrm{p}=.59)$ scores. 
Control participant:

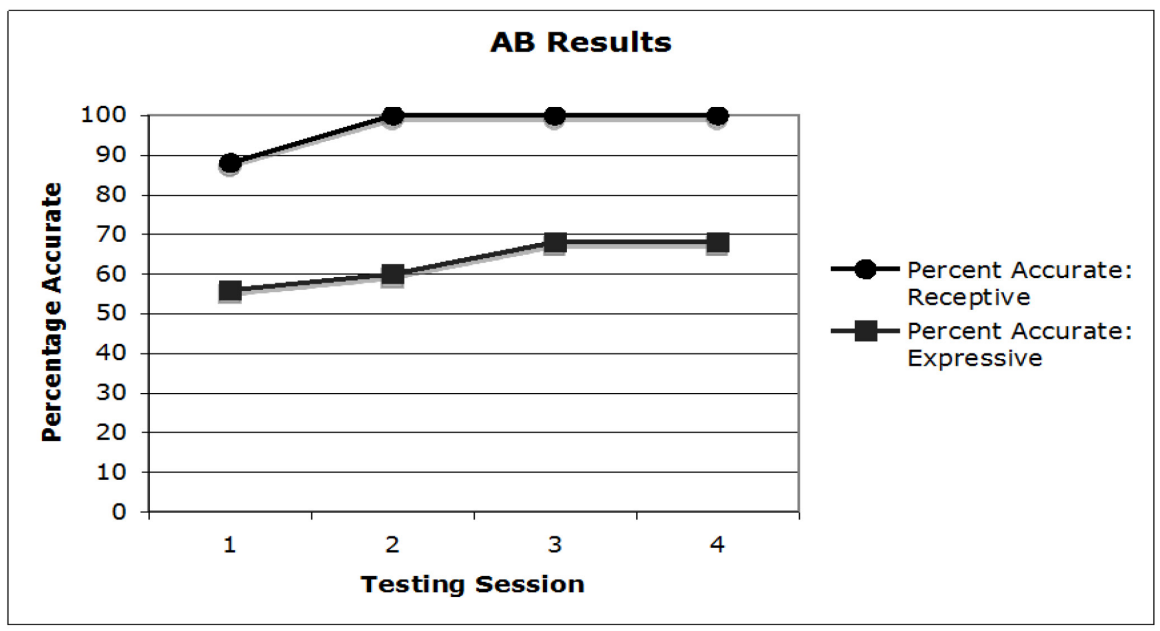

Children with speech sound disorders:
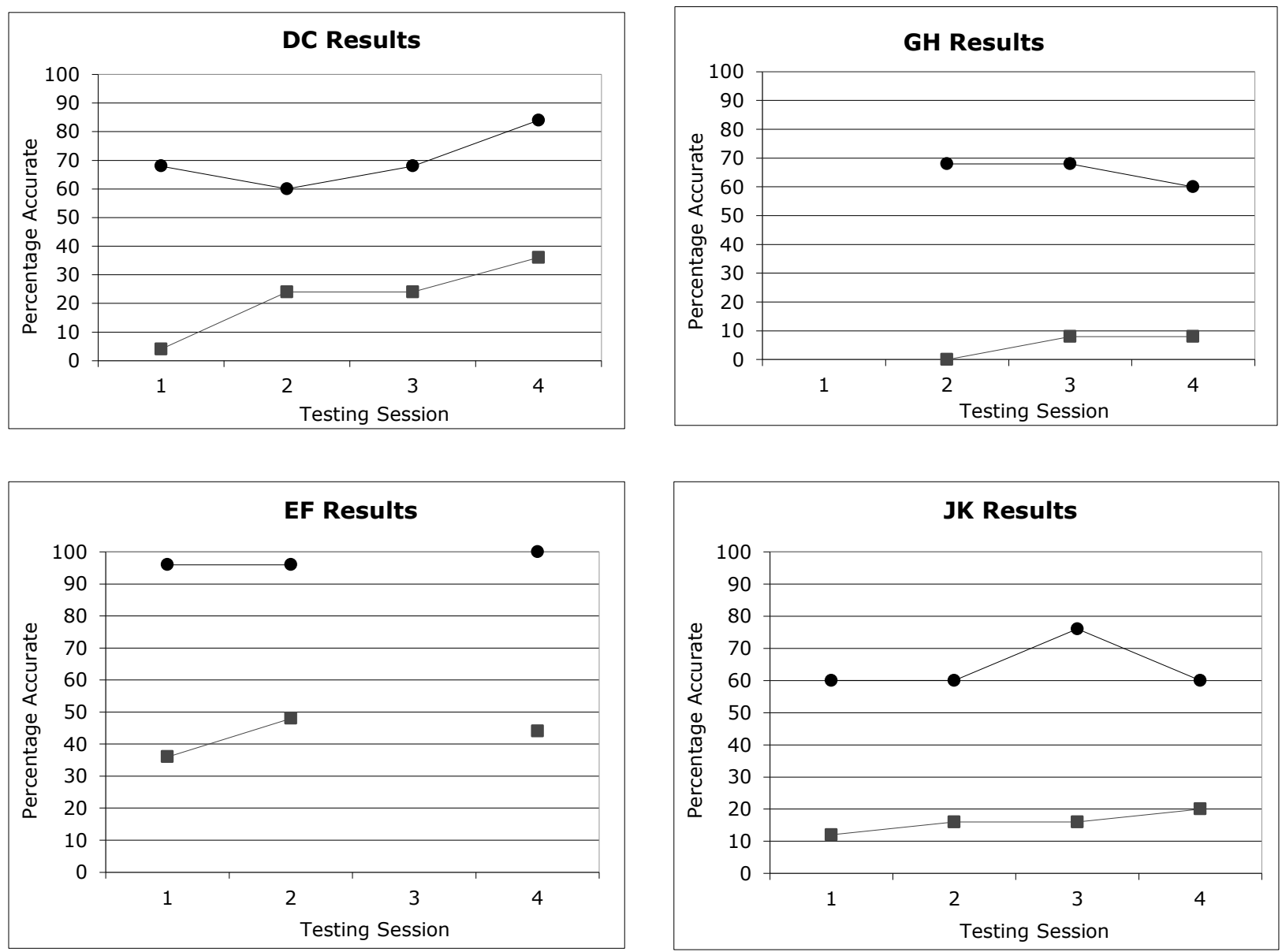

Figure 1. Results of Expressive and Receptive Vocabulary Accuracy for Control Participant and Children with Speech Sound Disorders. 


\section{Discussion}

This study investigates whether children with SSD acquire Spanish vocabulary similarly to typical peers over an eight-week period. The first research question addresses whether kindergartners with SSD would acquire Spanish vocabulary at a rate comparable to a typical peer. Acquisition rate was determined by comparing change in acquisition accuracy from session one to the final session of the typical peer against the average change in acquisition from session one to the final session for the students with SSD. Results showed that participants learned expressive vocabulary at a similar rate (14\% compared to $12 \%$ ), but did not learn receptive vocabulary at a similar rate (3\% compared to $12 \%)$. Interestingly, this comparable rate of expressive vocabulary acquisition occurred despite the fact that the control participant began the study demonstrating a higher number of expressive vocabulary words. The children with SSD began at a lower level of expressive ability and increased from that level, at a similar rate to the control participant.

The second research question addressed the differences between expressive and receptive vocabulary acquisition for participants with SSD, and in comparison to their typical peer. All children, including the control participant, showed superior accuracy in their receptive vocabulary comprehension over their expressive vocabulary abilities throughout the eight-week study. The investigator expected these results, given that most children learning their first language comprehend more words than they initially express (Hamaguchi, 2010).

Most of the participants with SSD began the study below the control participant in expressive and receptive abilities (with the exception of EF) yet all but one child increased over time in both the number of words acquired expressively and receptively. Interestingly, although there was a difference between the percent of expressive and receptive vocabulary acquired by all children, the difference between expressive and receptive vocabulary acquisition for those with SSD was even greater than that of the control participant (a difference of $32 \%$ between expressive and receptive vocabulary at the final probe session for the control participant compared to $40-56 \%$ for the children with SSD). Most children, when learning a language, experience a phenomenon called the "silent period," in which they focus on listening and comprehension and speak very little in order to put their efforts in first understanding the language (Roseberry-McKibbin \& Brice, n.d.). It appears that the children in this study excelled in their receptive abilities over their expressive abilities, which conforms to this 'silent period' phenomenon.

The higher receptive and expressive abilities of the control participant from the onset of the study, as well as greater gains by some participants with SSD, are open to interpretation. Factors that may have impacted overall acquisition include: (a) exposure to Spanish outside of the classroom, (b) the possible link between children who were late talkers at age two and those diagnosed with S/LD during school-age years, (c) vocabulary word preference and (d) degree of vocabulary exposure within each classroom. It is important to note that the investigator administered the initial study probe at a time when children had had no previous exposure to Spanish. Children were four months into their Spanish education at the time of the study, so the rates and impact of previous learning is unknown. Furthermore, although all children were 
selected based on their limited exposure to Spanish (all kindergartners beginning Spanish education for the first time), those children whose parents were willing to practice Spanish with them outside of the classroom and encouraged their use of Spanish would potentially be more capable of understanding and using Spanish vocabulary, although it is not possible to measure this factor within the scope of the study. Along with parental help, it is possible that the control participant's overall higher performance was due to experience previous to the study that the other children did not have; an example would be watching popular television programs like Dora the Explorer, which contains Spanish vocabulary words. Alternatively, there may have been a link between rates of acquisition and their SSD. Lower rates of acquisition experienced by these participants could be the result of a possible, as-yet unidentified, language difficulty. For example, late talkers, or children diagnosed at a young age with delayed expressive abilities, have been shown to have lower scores on language measures through age 8 when compared to typically-developing children (Rescorla, 2002). Identification of subsequent language problems, which late talkers are at risk for, might not occur until after a child's kindergarten year, yet would lead to poorer vocabulary acquisition in the first years of school. It is possible the children with SSD in this study had been late talkers, although this was unknown at the time of the study. Additionally, the investigator selected the vocabulary words used in this pilot study from a predetermined set within Spanish curriculum. It is possible that individual children prefer some words to others, and the words included in this list were not those that the children particularly liked or remembered best. Finally, although the investigator used a standard curriculum, students may have experienced different levels of vocabulary exposure in different classrooms.

The study sample was heterogeneous, as each child with a SSD learned the vocabulary at different rates. These results suggest some link between extent of the communication problem and acquisition. For example, at the beginning of the school year, DC was diagnosed with a unilateral hearing impairment and SSD, yet at the time of the study she was able to produce most of her mispronounced sounds correctly in conversation. DC showed the greatest rate of improvement out of all the children; it may be that the speech sound errors of the other participants with SSD had a greater impact on their learning of new vocabulary. GH, for example, had the most impacted communication as he had concomitant speech and language diagnoses. He began and remained lowest out of the participants in expressive vocabulary abilities, yet his receptive understanding was comparable to other children with SSD. This possible link between the extent of SSD problems and rate of acquisition is conjecture, given the heterogeneity of the sample.

Limitations of this pilot study included sample size and composition, study design, and methodology of the Spanish receptive vocabulary probe. Because only five participants were involved in this study, it is difficult to generalize these results over a large population of children. The number of participants was limited for this study based on both the limited number of kindergartners with S/LD at the test school and the amount of time available to test the participants. As previously noted, the sample of children with SSD was heterogeneous, further limiting the scope of the results. Additionally, a longitudinal study design may have been more successfully tracking change over a longer period of time and allowing for a study followup. Finally, the Spanish receptive vocabulary probe was a somewhat flawed methodology; it did 
not eliminate the possibility that children could simply guess by pointing at the correct picture flashcard without actually understanding the word spoken to them. Fluctuations in receptive test scores per child suggested this flaw; it is possible that scores decreased on any given day if the child was less successful at guessing. Given this knowledge, a more successful receptive vocabulary probe would include all 25 cards laid on the table at one time for the children to choose from, with selected correct or incorrect answers not revealed to the child. With this methodology, the chances of guessing would greatly decrease. A more thorough study design would be needed in order to further address the success of children with SSD in immersion schools.

The results of this study suggest that although children with SSD do not acquire as many Spanish vocabulary words as their mainstream classmates-a student following a normal school trajectory without extra academic help-they still acquired vocabulary words and increased the amount of words acquired over time. For some participants with SSD, their receptive abilities were comparable to the control participant, and the lag in their expressive abilities is not necessarily reason enough to exclude these children from immersion schooling. Genesee (1992) addressed a number of issues that place a child "at risk" in school, listing poor first language ability as one of those risk factors. Genesee (1992) stated that, "...without valid evidence concerning the suitability of immersion for children at risk in school, there is the danger that immersion programs could become elitist" (Genesee, 1992). Further research is needed to make immersion schools entirely accessible to all children, specifically research concerning the suitability of immersion schooling for children with S/LD, who might stand to benefit from such curricula as much, if not more, than their peers. Immersion schools are not intended to be elitist environments but are intended to share world languages with students to promote a more culturally aware society. The exclusion of certain groups of children was not the original aim of immersion schools and should not be a trend projected into the future.

\section{Acknowledgements}

I would like to first thank my primary advisor, Professor Karen McLaughlin, for all of her incredible advice and assistance, and for tirelessly editing my drafts. I would also like to thank Professors Kathleen Roberts and Samantha Hopkins, my second and third readers, for their support. A thank-you must be extended to the elementary school at which I conducted my primary research, and to the staff and teachers of that school, specifically Ana Quintero-Arias and Krista Kuykendall. Finally, I would like to thank my friends and parents for listening to all of my thesis concerns and for supporting me throughout this process, with a special thanks to Brooks Baumgartner for reading so many thesis drafts. I couldn't have done this without the love and support from everyone listed above.

\section{References}

Bowen, C. (1998). Children's speech sound disorders: Questions and answers. Retrieved from http://www.speech-language-therapy.com/phonol-and-artic.htm.

Bowen, C. (2009). Children's speech sound disorders. Chichester, U.K: Wiley- 
Blackwell.

Bruck, M. (1978). The suitability of early French immersion programs for the language-disabled child. Canadian Journal of Education / Revue canadienne de l'éducation, 3(4), 51-72.

Bruck, M. (1982). Language impaired children's performance in additive bilingual education program. Applied Psycholinguistics, 3(1), 45-60.

Campbell, R.N., Gray, T.C., Rhodes, N.C., \& Snow, M.A. (1985). Foreign language learning in elementary schools: A comparison of three language programs. The Modern Language Journal, 69(1), 44-54.

Council of chief state school officers: School matters. (2011). Retrieved from http://www.schoolmatters.com/schools.aspx/q/page $=s r / t x t=4 j / u s t=O R / p=1 / f p=1$

Christian, D. (1996). Two-way immersion education: Students learning through two languages. The Modern Language Journal, 8o(1), 66-76.

Cummins, J. \& Swain, M. (1986). Bilingualism in education: Aspects of theory, research and practice. London: Longman.

Dockrell, J., \& Messer, D. (1999). Children's language and communication difficulties: Understanding, identification, and intervention. London: Cassell.

Dodd, B. \& McIntosh, B. (2008). The input processing, cognitive linguistic and oro-motor skills of children with speech difficulty. International Journal of Speech-Language Pathology, 10(3), 169-178.

Felsenfeld, S., Broen, P.A., \& McGue, M. (1994). A 28-year follow-up of adults with a history of moderate phonological disorder: Educational and occupational results. Journal of Speech \& Hearing Research, 37(6), 1341-1353.

Genesee, F. (1987). Learning through two languages: Studies of immersion and bilingual education. Cambridge, MA: Newbury House Publishers.

Genesee, F. (1992). Second/foreign language immersion and at-risk English-speaking children. Foreign Language Annals, 25(3), 199-213.

Genesee, F., Paradis, J., \& Crago, M.B. (2004). Dual language development and disorders: A handbook on bilingualism and second language learning. Baltimore, MD: Paul H. Brookes Publishing Co.

Hamaguchi, P.M.A. (2010). Childhood speech, language, and listening problems: What every parent should know. Hoboken, N.J: Wiley.

Hegde, M.N. (Ed.). (1995). Introduction to communicative disorders (2nd Ed.). Austin, TX: PRO-ED, Inc.

Incidence and Prevalence of Communication Disorders and Hearing Loss in Children - 2008 Edition. (2008). Retrieved from http://www.asha.org/research/reports/children.htm.

Lambert, W.E., \& Tucker, G.R. (1972). Bilingual education of children: The St. Lambert experiment. Rowley, MD: Newbury House Publishers, Inc. 
Lazaruk, W. (2007). Linguistic, academic, and cognitive benefits of French immersion. Canadian Modern Language Review, 63(5), 605-628.

Leonard, L.B. (1998). Children with specific language impairment. Cambridge, Mass.: MIT Press.

Lewis, B. A., Shriberg, L. D., Freebairn, L. A., Hansen, A. J., Stein, C. M., Taylor, H., \& Iyengar, S. K. (2006). The genetic bases of speech sound disorders: Evidence from spoken and written language. Journal of Speech, Language \& Hearing Research, 49(6), 1294-1312.

Liberman, A.M., \& Whalen, D.H. (2000). On the relation of speech to language. Trends in Cognitive Sciences, 4(5) 187-196.

McCauley, R. (2004). Speech sound disorders in children: Description and classification. In R.D. Kent (Ed.) \& Massachusetts Institute of Technology. The MIT encyclopedia of communication disorders. Cambridge, Mass: MIT Press.

McGregor, K. (n.d.). Speech and language impairments. Retrieved from http://www.education.com/reference/article/speech-and-language-impairments/\#C.

National Institute on Deafness and Other Communication Disorders (U.S.). (2000). Speech \& language: Developmental milestones. Bethesda, Md: National Institute on Deafness and Other Communication Disorders. Retrieved from

http://web.archive.org/web/20010303065328/www.nidcd.nih.gov/health/parents/speecha ndlanguage.htm

Peterson, R.L., \& McGrath, L.M. (2009). Speech and language disorders. In B.F. Pennington (Ed.), Diagnosing learning disorders: A neuropsychological framework. (83-107). New York: Guilford Press.

Roseberry-McKibbin, C., \& Brice, A. (n.d.) Acquiring English as a second language. Retrieved from http://www.asha.org/public/speech/development/easl.htm

Rescorla, L. (2002). Language and Reading Outcomes to Age 9 in Late-Talking Toddlers. Journal of Speech, Language \& Hearing Research, 45(2), 360-371.

Sinatra,R. (2008). Creating a culture of vocabulary acquisition for children living in poverty. Journal of Children \& Poverty, 14(2), 173-192.

Stewart, J.H. (2005). Foreign language study in elementary schools: Benefits and implications for achievement in reading and math. Early Childhood Education Journal, 33(1), 11-16.

Trites, R. (1981). Primary French immersion: Disabilities and predictions of success. Review and Evaluation Bulletins: Ontario Ministry of Education, 2(5), 1-75.

Turnbull, M., Lapkin, S., \& Hart, D. (2001). Grade 3 immersion students' performance in literacy and mathematics: Province-wide results from Ontario (1998-99). The Canadian Modern Language Review, 58(1), 9-26.

U.S. Census Bureau. (2009). School enrollment. Retrieved from http://www.census.gov/hhes/school/data/cps/2009/tables.html 
U.S. Department of Education. (2005). To assure the free appropriate public education of all Americans: Twenty-seventh annual report to Congress on the implementation of the Individuals with Disabilities Education Act. Retrieved from http://www.ed.gov/about/reports/annual/osep/2005/index.html

Varley, R. (2008). Substance or scaffold? The role of language in thought. In V. Joffe, M. Cruice, \& S. Chiat. (Eds.), Language disorders in children and adults: New issues in research and practice (138-158). Chichester, U.K: Wiley-Blackwell.

Webster, R. I., \& Shevell, M.I. (2004). Neurobiology of specific language impairment. Journal of Child Neurology, 19(7), 471-481. 


\section{Appendix A}

Table A.1. Vocabulary

\begin{tabular}{|c|c|}
\hline $\begin{array}{l}\text { Spanish Vocabulary } \\
\text { Words }\end{array}$ & English Equivalent \\
\hline Niño & Boy \\
\hline Niña & Girl \\
\hline Escuela & School \\
\hline Mochila & Backpack \\
\hline Basura & Trash/garbage \\
\hline Maestra & Teacher \\
\hline Baño & Bathroom \\
\hline Zapato & Shoe \\
\hline Ventana & Window \\
\hline Puerta & Door \\
\hline Ojo & Eye \\
\hline Nariz & Nose \\
\hline Cabeza & Head \\
\hline Avión & Airplane \\
\hline Brazo & Arm \\
\hline Lápiz & Pencil \\
\hline Pies & Feet \\
\hline Papel & Paper \\
\hline Chaqueta & Jacket \\
\hline Libro & Book \\
\hline Silla & Chair \\
\hline Mesa & Table \\
\hline Estrella & Star \\
\hline Mano & Hand \\
\hline Boca & Mouth \\
\hline
\end{tabular}

